\title{
ANTICOAGULANT INDUCED LIFE THREATENING CORPUS LUTEAL CYST HAEMORRHAGE
}

Uma Thombarapu ${ }^{1}$, Gangadhara Rao Koneru², Prabha Devi Kodey³

\section{HOW TO CITE THIS ARTICLE:}

Uma Thombarapu, Gangadhara Rao Koneru, Prabha Devi Kodey. "Anticoagulant Induced Life Threatening Corpus Luteal Cyst Haemorrhage". Journal of Evolution of Medical and Dental Sciences 2015; Vol. 4, Issue 45, June 04; Page: 7874-7877, DOI: 10.14260/jemds/2015/1148

ABSTRACT: This is presentation of woman on unmonitored anticoagulants with life threatening haemoperitoneum.

KEYWORDS: Corpus luteum, Haemorrhage, Anticoagulants.

INTRODUCTION: Ovulation is a physiological event in reproductive age group women. After ovulation Corpus luteum develops from residual follicular granulosa and thecal cells. At the end of menstrual cycle or during pregnancy, it regresses spontaneously. Sometimes haemorrhage can occur in corpus luteal cyst leading to rupture of cyst and hemoperitoneum. The same might lead to life threatening event in women with anticoagulants. In this case the woman who underwent Mitral valve replacement (Rheumatic heart disease) on oral anticoagulants presented with significant haemoperitoneum, on whom we did laparotomy proceeded with left salpingo- Oopherectomy. This report stresses the regular follow up of these women even though they do not have other bleeding manifestations.

CASE REPORT: A 34 yrs. old parous lady admitted in labour room as an emergency with pain abdomen and syncopal attacks of one day duration. She was admitted in another hospital for the same. Ultra sound abdomen and pelvis was done. She was diagnosed as ovarian cyst with torsion and same day patient was referred to our hospital for further management.

Patient underwent prosthetic mitral valve replacement for mitral stenosis 17 years back, again under went cardiac surgery for mitral valve restenosis 6 years back. She had been on Tablet Aceno Coumarol 3mg/day and was on irregular follow up. Patient had regular menstrual cycles 3-4 days/28-30 days, normal flow, last menstrual period 35 days back. Married for 14 years, P2L2, both normal vaginal deliveries, no h/o usage of any contraception in between deliveries and last child birth was 6 years. She underwent puerperal sterilisation. At admission patient was conscious and coherent. She was severely pale, afebrile, pulse rate $110 /$ minute, respiratory rate $20 /$ minute, blood pressure $90 / 60 \mathrm{~mm}$ of $\mathrm{Hg}, \mathrm{SpO}_{2} 96 \%$ at room air, prosthetic valve click at mitral area and bilateral vesicular breath sounds present. Per abdomen, guarding and diffuse tenderness present. Per speculum examination cervix healthy. Bimanual examination: cervix downwards, uterus size could not be made out, bilateral forniceal tenderness and cervical movement tenderness present. With this history we put the provisional diagnosis as ruptured ectopic pregnancy or haemorrhagic ovarian cyst.

Her investigations revealed: Hemoglobin 4.3 gm\%, Prothrombin time (PT): 97.5 sec, INR 9.0, Platelet count: 2.49 lakhs/cumm, urine hCG test- negative, renal and liver function test normal. USG abdomen and pelvis revealed complex mass of $11 \times 9 \mathrm{cms}$ in pelvis postero- lateral to the uterus. Free fluid in the abdomen and pelvis with internal echoes - possible ectopic pregnancy or complex ovarian cyst with rupture and haemorrhage. ECG-normal. ECHO - Normally functioning prosthetic Mitral 
valve, Mild para valvular leak, mild MR, severe TR, moderate PAH, dilated RA and RV, normal LV systolic function, EF: 0.65, no clots and pericardiac effusion. After transfusing 2 packed red blood cells (PRBC) and 4 units fresh frozen plasma (FFP), patient was taken up for surgery. Preoperatively Injection Ceftrioxone and Gentamycin were given. $1000 \mathrm{ml}$ of hemoperitoneum and 400gms clots were evacuated from abdomen. Right ovary normal, right tube shortened, left tube found normal, and there was no sign of tubectomy. Left ovary enlarged $5 \times 6 \mathrm{cms}$, rent in the posterior surface of ovary and active bleeding was present, near to that a fleshy mass appeared? Products of conception. With the doubt of ovarian ectopic left salpingo opherectomy done. Tubectomy done on right side. Peritoneal wash given. Post operatively PT -15.68 seconds, INR- 1.26, Hb\%- 6.4 gm/dl, 2 FFPs and 2 units of packed cells (RBC) were given. On post-operative day (POD) 1- Hb\%- 9.1gm/dl, PT- $13.4 \mathrm{sec}$, INR- 1.06, injection Heparin 5,000IU subcutaneously started 6 th hourly. POD - 3 Tablet Aceno coumarol $1 \mathrm{mg}$ / day started along with Heparin, POD 6- Heparin tapered to $8^{\text {th }}$ hourly, suture removal done, wound healthy. POD 8- Heparin stopped and oral Aceno coumarol given $2 \mathrm{mg} / 3 \mathrm{mg}$ on alternate days. At the time of discharge PT-17.11 seconds, INR-1.4. Patient was advised for follow up after 4 weeks. This patient requires Ovulation suppression for preventing corpus luteal cyst haemorrhage subsequently.

Histopathology Report showed: No evidence of products of conception. Tube - normal. OvaryCorpora albicantia, cystic follicles and haemorrhagic corpus luteum.

DISCUSSION: After Ovulation, the remaining follicular cells are transformed into corpus luteum, which is primary regulator of the luteal phase. Granulosa cells that remind in the follicle begin to take up lipids and the characteristic yellow leutin pigment for which the structure is named ${ }^{1}$. Corpus luteum function depends upon the continued Leutinising hormone production. In the absence of its stimulation, corpus luteum will regress after 12 to 16 days to form a scar-Corpora albicans. But sometimes, it may be filled with fluid or blood, causing the corpus luteum to expand to form a cyst, which is less common than the follicular cyst. Corpus luteum is a thin walled vascular structure, prone to haemorrhage even bleeding is usually contained into the cyst or sometimes ruptured into the peritoneal cavity. ${ }^{2}$

Corpus luteum may rupture leading to hemoperitoneum. It may occur spontaneously or triggered by coitus, trauma, exercise or vaginal examination. The real risk of haemorrhage in normal population is not known. Patient taking anticoagulant therapy or with bleeding diathesis are at particular risk for haemorrhage and rupture. In these people it may be fatal in 3\% $-11 \%{ }^{3}$ Most often cyst rupture may occur between $20^{\text {th }}-26^{\text {th }}$ day of menstrual cycle. The severity of the patient's signs and symptoms with corpus luteum haemorrhage depends upon the extent of bleeding and the dose of anti-coagulants they are using, ${ }^{4}$ regular monitoring with PT/INR may reduce this incidence.

Haemorrhagic corpus luteum may develop at any age group, more commonly associated with the early period after menarche, and they are commonly associated with dysfunctional ovulation. Corrpus luteal cyst rupture is more common on right side, as left is protected by rectosigmoid colon, ${ }^{5}$ and also increased intraluminal pressure and differences in Ovarian vein architecture. ${ }^{6}$ The symptoms of corpus luteal hemorrage are similar to ruptured ectopic pregnancy and important in differential diagnosis in reproductive age women. ${ }^{7}$

Here we discussed a case report in 34 years old patient with 35 days ammenorhea presented with hemoperitoneum, with which ectopic pregnancy is important differential diagnosis. Even though her urine HCG test was negative we were not sure to rule out ectopic pregnancy. History of 
tubectomy was there, but intra operatively on right side tube shortened but no discontinuation of tube seen and on left side tube was normal. A fleshy mass nearly attached to left adnexae, gave us suspicion of ruptured ectopic, therefore we proceeded with left salpingoopherectomy. Tubal ligation done on right was side. Even though this helps women not to conceive, it would not protect from recurrence on corpus leutal cyst hemmorage. The risk of recurrence in women with coagulation disorders is $25 \%-31 \%$.

These set of people requires ovulation inhibition, to prevent recurrence in addition to contraception. It is even more difficult in women with metallic valve replacement and on anticoagulants. According to "WHO Eligibility Criteria - for Contraception 2009". 8 combined oral contraceptive pills with both estrogen and progesterone are under category-2 in women with valvular heart disease without complications and category-4 with complications. Progestin only pills, DMPA and NET EN are in category-1 in women with valvular heart disease with or without complications. (Category 1-can use the method. No restriction on use. Category 2 - can use the method. Advantages generally out-weigh theoretical or proven risk. Category-3-should not use the method. Theoritical or proven risk usually outweigh the risks. Category-4-should not use the method. Condition represents an unacceptable health risk if method is used).

CONCLUSION: Women with valvular heart disease with valve replacement on anticoagulants should be under regular follow up for their coagulation status, as they might land up in complications like corpus luteal hemorrhage without any other bleeding manifestations. These women might require safe ovulation inhibition not only for those who doesn't want pregnancy, but also to prevent corpus luteal haemorrhage.

\section{REFERENCES:}

1. Jonathan S Bereck, Bereck and Novark Gynaecology, 15 th Edition, 2012; Lippincott Williams \& Wilkins, Philadelphia, Page No: 155, Chapter 7.

2. Andrew W. Potter, chitra A Chandrasekhar - "US and CT evaluation of acute pelvic pain of gynecologic origin in nonpregnant premenopausal patients," Radiographics, 2008; vol. 28: $1645-1659$.

3. Ho WK, Wang YF, Wu HH, Tsai HD etal: Ruptured corpus luteum with hemoperitoneum: case characteristics and demographic changes over time. Taiwan j obstet gynecol 2009, 48: 108-112.

4. Wadha Al Ghafri, Vaidyanathan Gowri etal Gynaecology 2013, htpp: //www. hoajonline.com/journals/pdf/2052-6210-1-2.

5. Payne JH, Maclean RM, Hampton KK, Baxter AJ and Makris M: Haemoperitoneum associated with ovulation in women with bleeding disorders: the case for conservative management and the role of the contraceptive pill. Haemophilia 2007, 13: 93-7.

6. B. Tang LC, Cho HK, Chan SY, Wong VC, Dextro preponderance of Corpus Luteum rupture: A clinical study; Journal of reproductive medicine 1985; 30: 764-8.

7. Jonathan S Bereck, Bereck and Novark Gynaecology, 15th Edition, 2012; Lippincott Williams \& Wilkins, Philadelphia, page no 474-chapter 16.

8. World Health Organization: Medical Eligibility Criteria for Contraceptive Use (4th edition); 2009. 


\section{CASE REPORT}

\section{AUTHORS:}

1. Uma Thombarapu

2. Gangadhara Rao Koneru

3. Prabha Devi Kodey

\section{PARTICULARS OF CONTRIBUTORS:}

1. Assistant Professor, Department of Obstetrics \& Gynaecology, NRI Medical College \& General Hospital.

2. Professor, Department of Obstetrics \& Gynaecology, NRI Medical College \& General Hospital.

3. Professor \& HOD, Department of Obstetrics \& Gynaecology, NRI Medical College \& General Hospital.

FINANCIAL OR OTHER COMPETING INTERESTS: None

\section{NAME ADDRESS EMAIL ID OF THE CORRESPONDING AUTHOR:}

Uma Thombarapu MD, Assistant Professor, Department of Obstetrics \& Gynaecology, NRI Medical College \& General Hospital, Chinakakani, Mangalagiri Mandal, Guntur-522503.

Andhra Pradesh, India.

E-mail: umathombarapu@gmail.com

Date of Submission: 13/05/2015. Date of Peer Review: 18/05/2015. Date of Acceptance: 27/05/2015. Date of Publishing: 04/06/2015. 